\title{
LOS MUERTOS SE EMBORRACHAN
}

\author{
por \\ M. MANDIANES
}

Mi encuesta se limita a la Limia, a las tierras de Vilardevos y Laza (Verín). Los datos referentes al resto de Galicia los tomo de encuestas y trabajos de otros autores que, además, dan este una dimensión histórica imprescindible. Refiriéndose a la Limia decía un autor del siglo XVIII: Los frutos de la planicie y montes poco ásperos que la circundan son mucho centeno, algún trigo, mijo grueso y menudo, lino, patatas, toda especie de legumbres y de hortaliza, castaña, frutas y ningún vino, aunque se embasa mu$c h{ }^{1}$. Refiriéndose a los montañeses del noroeste de la Península, dice un autor clásico: Todos los habitantes de la montaña llevan una vida sencilla, beben agua... Andan escasos de vino y el que consigue lo consumen rapidamente en banquetes familiares ${ }^{2}$. Me limitaré a estudiar el consumo ritual de alcohol a través del ciclo anual y de vida.

\footnotetext{
${ }^{1}$ Pedro González de Ulloa, Descripción de los Estados de la casa de Monterrey en Galicia (1777? Ed de J. Ramón y Fernández Oxea. Consejo Superior de Investigaciones Científicas-Cuadernos de Estudios Gallegos. Anexo IV, Santiago de Compostela 1950), p. 116.

${ }^{2}$ Estrabón, III, 3, 7.
}

"CUADERNOS DE ESTUDIOS GALLEGOS", Tomo XL, Fascículo 105, Santiago 1992. 


\section{El ciclo anual}

Los hombres de la Limia todos los días por la mañana, antes de salir de casa, tomaban una copa de aguardiente con pan porque por la mañana hace mucho frío. Pero también la tomaban en verano que no hace tanto aunque sea temprano. En realidad, se podían encontrar con las brujas sobre todo en las encrucijadas de los caminos y la aguardiente los protegía de ellas. Cuando alguien se hacía daño, le echaban unas gotas de aguardiente en la herida y desinfectaban con ella.

A la forja solo iban hombres para arreglar o hacer nuevas las herramientas de la labranza. Muchas veces descotabamos y mandábamos a uno a comprar vino, cada uno llevaba de su casa lo que podía: pán y un poco de carne, y merendábamos allí. Asábamos en las brasas de la forja las cortezas del tocino. Hablabamos de cosas de hombres como en el horno en donde se juntaban los hombres como en la forja; las mujeres solo iban al horno cuando le tocaba el turno a su casa. Los sacerdotes no podían frecuentar los lugares de hombres ${ }^{3}$, solo para comer y beber cuando iban de viaje $^{4}$.

La mujer que recogió la sangre, u otra, baja un caldero o una palangana de auga caliente para que los hombres laven las manos en el fondo de la escalera; el matón es el último en lavarse porque es el que tiene las manos más sucias. Todos, incluídos niños y mujeres, toman una copa de aguardiente en el fondo de la escalera antes de subir a la cocina para desayunar. Las mujeres el día de la matanza van a lavar las tripas siempre al río; a la vuelta toman vino caliente con miel al lado del fuego de la lareira. Las mujeres también lo tomaban el día del tascadeiro, en la misma cuadra o en la cocina al lado del fuego ${ }^{5}$. Los hombres lo toman el día de la limpa del grano del centeno: acarrean el grano en sacos desde la era a los arcaces y cada vez que van toman vino con miel que está al lado de uno de los arcaces ${ }^{6}$.

El día de la fiesta del pueblo, por la mañana temprano, los músicos

\footnotetext{
${ }^{3}$ SH, I, Mond 19 (1534), 30, p. 62; 48, p. 68; Orense 28-29 (1543-44), 6. 16, p. 191; II, Braga 1 (1281, 36; guarda 1 (1500), 62; Sínodo de Or. 1622, p. 130; Sínodo de Or. de 1908, p. 103.

${ }^{4}$ SH, I, Mond. 19 (1534), 23, p. 59; 48, p. 68; Orense 28-29 (1543-44), 6. 8, p. 187.

${ }^{5}$ M. Mandianes, $O$ fiadeiro na Limia Alta, en Grial XXIV, 90 (1985), p. 414-430.

${ }^{6}$ M. Mandianes, A seitura na Limia Alta, en Grial XXI, 81 (1983), 287-300.
} 
acompañados de los mayordomos, iban dando por los caminos y por los patios de las casas, la alboarada. Al oirlos, los de cada casa y sus invitados bajaban al patio para bailar o salían sencillamente al alto de la escalera para hacer los honores a la música. Al terminar de interpretar sus piezas una mujer de casa bajaba al patio con una bandeja y copas y una botella o sencillamente con una botella de aguardiente y una copa. Y daba la copa a todos los presentes que bebían por la misma copa.

Los días de Carnaval todo dios se emborrachaba. Muchos cogen la melopéa la víspera y no la apean hasta el día después (Laza). La gente bebe hasta verte cristo mío (Xinzo de Limia); es como si la gente viviese para beber (Verín). En el carnaval de Laza, además de aguardiente y licor café, también se toma mucho vino como en los momentos de integración: el magosto, los banquetes y las fiestas saciales. Los autores que tratan del magosto hacen resaltar el ambiente festivo del mismo y la abundancia de vino que los participantes consumen ${ }^{7}$. El samahaim, fiesta del comienzo del año celta de la que la de los Fieles Difuntos sería la cristianización ${ }^{8}$ y el magosto su continuación en Galicia, terminaba en borrachera colectiva ${ }^{9}$. No se puede mear en él, pero algunos, borrachos como cubas, se mean en el fuego del magosto y en su padre, si hace falta. Las únicas veces que me emborraché fueron los días de magosto; una buena parte de los participantes se emborrachaban esos días ${ }^{10}$.

\section{O viño da memoria}

En el agua del primer baño del recién nacido echaban una moneda de plata para que el niño fuera rico y vertían unas gotas de vino de la memoria, que mantiene vivo el recuerdo de los muertos. En la Limia Alta daban a beber unas gotas de vino al recien nacido. El mismo día del bautismo, después de

${ }^{7}$ A. Fraguas, Galicia insólita (Libregal, Coruña 1973), 234 pp., p. 212; N. Tenorio, La aldea gallega (Cádiz 1914. Ed. fascimil. Xerais, Vigo 1982), p. 108.

${ }^{8}$ A. Varagnac, Les traditions populaires (PUF, Paris 1978), 128 pp., p. 39.

${ }^{9}$ J. de Vries, La religion des Celtes (Payot, Paris 1963), 279 pp., p. 237; J. Markale, Le christianisme celtique et ses survivances populaires (Imago, Paris 1983), $260 \mathrm{pp}$., p. 186-189.

${ }^{10}$ Cfr. N. Tenorio, op. cit., p. 108; C. Lisón, Antropología cultural de Galicia (Siglo XXI, Madrid 1971), p. 147; A. Fraguas, op. cit., 212.

"CUADERNOS DE ESTUDIOS GALLEGOS", Tomo XL, Fascículo 105, Santiago 1992. 
llegar de la iglesia o un día después, los padrinos daban la copa a todas las casas del pueblo que consistía en una copa de aguardiente y un pedazo de pan. Eso ya desapareció; ahora el que quiere la va a tomar a la casa de la criatura o el padrino invita en el bar a los hombres que encuentra alli ese día. Antes, dice una señora de 75 años, en nuestra parroquia (Aguís) el padre del niño daba una merienda: pan, chorizos y vino, en la sacristía al cura y a los padrinos. El asistía pero no comía. En Junquera de Ambía (Orense) al regresar de la iglesia, entregan el niño a la madre y se sientan a la mesa donde de antemano se ha preparado la merienda que consiste en torradas, huevos cocidos con salsa de miel de abeja, bebiendo de la olla de vino reservada a la parturienta ${ }^{11}$. La mujer en cuarentena de parto tenía su vino reservado porque era creencia generalizada que era bueno para la recuperación. Una botella de vinno dulce casi siempre hacía parte de la cesta que cada una de las otras casas de la aldea llevaba a la mujer en cuarentena de parto.

\section{A copa da boda}

El mozo, el primer día que iba a las mozas, en la taberna del pueblo de la moza, casi siempre se emborrachaba con los otros mozos de su pueblo. La noche antes de marcharse los quintos al servicio militar también salían todos los mozos del pueblo y tomaban bastante vino. En Villameá antes de hacerse la primera amonestación la vispera de ella, el novio acompañado de su amigo de más confianza concurren a la casa de la novia para hacer las proclamas o pregós llevando una bota de vino para cenar en compañía de la familia de la novia ${ }^{12}$. Cuando llegaba la hora de casarse ${ }^{13}$ el mozo, con su padre y un tío o algún amigo, iba a pedir la moza. Los esperaban los padres de ella en la puerta de la casa. El mozo se sentaba en una silla que las mozas de casa habían pasado por el fuego de la lareira en torno al cual tenía lugar la ceremonia. La moza no asistía a la reunión. Terminaban merendando pan-

${ }^{11}$ Encuesta del Ateneo de Madrid sobre el cicio de vida, 1901 (Copia en el Arxiu Carreras i Artau. Mila i Fontanals, C.S.I.C., Barcelona), I, D.

${ }^{12}$ Encuesta del Ateneo..., II

${ }^{13}$ L. Carré, O casamento nas aldeas de Galicia, en Rev. de Etnog. XVI (1972), 335345; X. Lorenzo, Casamento en Loveira, en Nós V, n. 58, 186.

"CUADERNOS DE ESTUDIOS GALLEGOS", Tomo XL, Fascículo 105, Santiago 1992. 
trigo, chorizos y vino tinto. El mozo que se casaba con una moza de fuera de la parroquia debía pagar el vino a los mozos de la parroquia de la novia; cuanto más guapa y buena moza, más vino tenía que pagar. En los pueblos de la Limia Alta, hasta los años setenta la gente solo celebraba el santo. Cada casa que tenía un santo invitaba a las otras a tomar la copa.

Desde la mañana temprano, el día de la boda la casa de la novia era una fiesta; mientras ella se preparaba y se vestía, casi siempre de negro, otros miembros de la casa preparaban a parva, para que los invitados desayunaran antes de salir para la iglesia. Si los novios eran de parroquias diferentes, él llegaba con sus invitados a la casa de ella y todos tomaban aquí a parva: un pedazo e pan o de roscón y una copa y, luego, salían juntos para la iglesia; si eran de la misma parroquia los invitados tomaban la parva en casa del que los había invitado y desde allí salían para la iglesia, en dos cortejos.

Las bodas de antes eran las de verdad; se celebraban en casa durante tres o cuatro días. La gente comía hasta reventar y bebía hasta emborracharse. El segundo día de la boda los novios salían por el pueblo de ella a dar la copa a las casas que no habían estado en el banquete, y un día después lo hacían en el del novio; todo el mundo participaba. En varios pueblos a los vecinos se les repartía pan, carne y vino ${ }^{14}$.

\section{Os mortos emborrachanse}

Los que preparaban el cadáver, al terminar, tomaban con todos los presentes una copa de aguardiente. Hacia las tres de la mañana unas mujeres amigas de la casa daban una copa, también de aguardiente, a todos los que estaban en el velorio. No era raro que una parte de los invitados al banquete funerario terminaran borrachos. Cuentan que un sacerdote un día dijo en misa: triunfan bastos, en vez de decir: dominus vobiscum porque la víspera había ido a un entierro y había pasado toda la noche jugando al tresillo y bebiendo. Los orificios al cadáver se le taponaban con estrías de lino empapadas en aguardiente. En Carbía la familia pone a la disposición de los que velan algo con que restituir la falta de descanso, y que suele ser en las aldeas, aguardiente, vino y pan. En los pueblos, café o chocolate ${ }^{15}$. En

\footnotetext{
${ }^{14}$ Encuesta..., II.

${ }^{15}$ Encuesta..., III.
}

"CUADERNOS DE ESTUDIOS GALLEGOS", Tomo XL, Fascículo 105, Santiago 1992. 
Villar de Monte velan el cadáver la familia y los amigos, y con tal motivo se come y bebe en abundancia ${ }^{16}$. Una de las cosas que no faltan en un velorio gallego es el alcohol. Los hombres, también para ayudar a matar el tiempo, tomarán buen cuidado para que la botella no ande mucho tiempo lejos de ellos durante la noche; en resulta es que, después de las primeras horas, la sobriedad brilla por su ausencia, tal vez para crear un ambiente de irresponsabilidad que permita, sobre todo al mozo enfrentarse con la muerte ${ }^{17}$.

En el ayuntamiento de Forcarey van delante del ataud... varias mujeres llevando cestas con pedazos de pan y botas de vino... Después de verificada la inhumación las lloronas comen y beben en el mismo atrio-cementerio, sentadas en derredor de las cestas ${ }^{18}$. En algunos pueblos llevaban a la sacristía la parva: pan y vino, para los sacerdotes que venían de lejos, y en otros, los derechos se pagaban en vino ${ }^{19}$.

En varios pueblos de Galicia, antes, los ricos matan un buey o una vaca con objeto de tener comida para los forasteros, parientes, amigos, clero, etc. ${ }^{20}$. En la Limia el vino corría en abundancia durante todo el banquete del día del entierro. Algunos comensales terminaban borrachos, me dijeron. Los Sínodos diocesanos prohiben a los clérigos que vayan a la casa de los feligreses a tomar parte en tales banquetes, entre otras razones, porque corrían el peligro de escandalizarlos por beber demasiado. Otrosi proybimos quel dia de los enterramientos no ay a comidas ni bevidas por los clerigos con los herederos ni executores de los testamentos, y si algunos drechos oviere de aver los ayan en dineros y no en comidas ni en bevidas, so pena de un ducado para la fabrica de la yglesia; excepto sifueren a otros lugares llamados, que en tal caso puedan comer y bever con ellos ${ }^{21}$. Los contemporáneos de M. Dumiense derramaban vino sobre los troncos

\footnotetext{
${ }^{16}$ Encuesta..., III.

${ }^{17}$ M. Gondar, Romeiros do Alén (Xerais, Vigo 1989), p. 110.

${ }^{18}$ A. García Ramos, Arqueología jurídico-consuetudinaria-económica de la región de Galicia (J. Ratés, Madrid 1912. Red fascimil de la Xunta s/a), 195 pp., p. 24.

${ }^{19}$ Encuesta..., III.

${ }^{20}$ Encuesta...., III.

${ }^{21}$ Synodicon Hispanum, op. cit., I, Tuy 6 (1528), lib. 3, tit. 12.4, p. 474; cfr. Mond. 19 (1534), 39, p. 65; 22 (1521), 3, 11-12.19, p. 75-77; 23 (1547), 6, p. 84; Orense 28-29 (1543-44), 6.1, p. 107; Tur 6 (1528), lib. 3, tit. 11.1, p. 470-71; II, Braga 26 (1477), 33, p. 107; Const. del Sínd. de Or. de 1619, lib. 2, tit. 2, const. 1, p. 130.
}

"CUADERNOS DE ESTUDIOS GALLEGOS", Tomo XL, Fascículo 105, Santiago 1992. 
encendidos lo que según él es dar culto al diablo ${ }^{22}$ y según mi parecer no es más que dar de beber a los muertos ${ }^{23}$. Los Sínodos diocesanos gallegos dicen que los muchachos en las rogas de difuntos pedían vino ${ }^{24}$. En la Gudiña, algunas aldeas como Punxeiro y otras conservan la práctica de colocar el día de los fieles difuntos en el cementerio, sobre la sepultura de los muertos, un pan de dos libras y un jarro de vino ${ }^{25}$.

\section{CONCLUSION}

La aguardiente acompaña a los ritos de pasaje, el momento de dar el paso: bautismo, matrimonio y muerte. Así como el momento inmediatamente posterior a la matanza de los cerdos, el momento de salir por la mañana de casa: momento verdadero de pasar de un día a otro; hasta este momento era la noche para quien es. Los ritos, sin embargo, de integración, se celebran con vino: los banquetes de bautismo, boda y entierro. También se celebran con vino la integración del rapaz al grupo de los mozos y del mozo al grupo de los hombres con su marcha al servicio militar.

${ }^{22}$ M. Dumiense, De correctione rusticorum, n. 16, en Martini Episcopi Bracarensis Opera Omnia (Ed. C.W. Barlow. New Haven 1950), p. 198.

${ }^{23}$ J. Rodríguez López, Supersticiones de Galicia y preocupaciones vulgares (1895. Ed. Celta, Lugo 1974), 276 pp., p. 129-131.

${ }^{24} \mathrm{SH}$, I, Mond. 22 (1541), 3, 11, p. 73-75; item, 16, p. 77; Tuy 6 (1528), lib. 3, 12.4, p. 474; II, Braga 1 (1281), 33, p. 20-21; Braga 26 (1477), 23, p. 96-97; Guardia 1 (1500), 57, p. 255.

${ }^{25}$ N. Tenorio, La aldea gallega, op. cit., p. 110.

"CUADERNOS DE ESTUDIOS GALLEGOS", Tomo XL, Fascículo 105, Santiago 1992. 